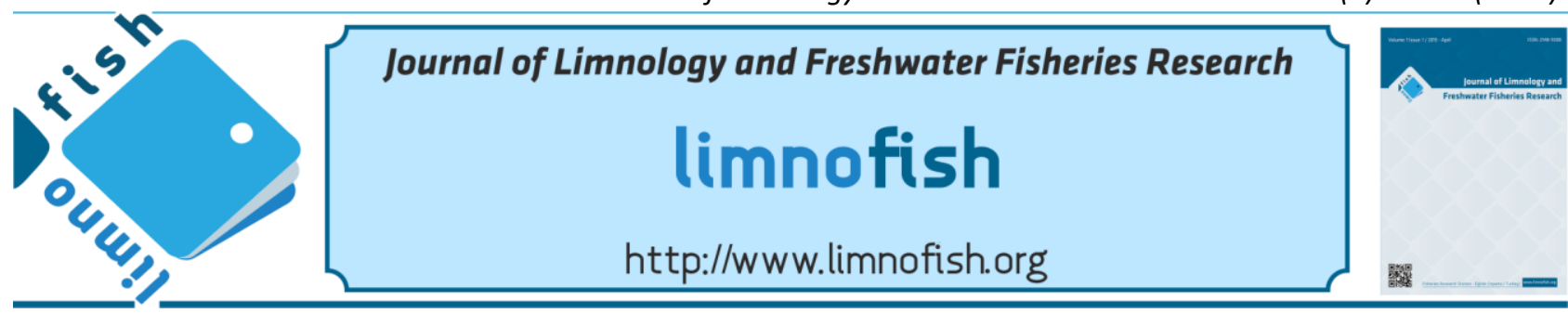

\title{
İstilacı Gambusia Türlerinin (Gambusia holbrooki ve G. affinis) Özellikleri, Türkiye'deki Durumları ve Oluşturdukları Ekolojik Riskler
}

\author{
Irmak KURTUL*, Hasan M. SARI \\ Ege Üniversitesi, Su Ürünleri Fakültesi, Su Ürünleri Temel Bilimler Bölümü, 35100, Bornova, İzmir, Türkiye
}

$\ddot{o} Z$

Bu çalışmada, özellikle endemik türlerin devamlılığı açısından risk oluşturduğu belirtilen iki sivrisinek balığı türünün sistematik özellikleri, Türkiye'deki dağılımları, morfolojik ve ekolojik özellikleri, habitat ve besin tercihleri ile üreme özellikleri hakkında bazı bilgiler verilmiştir. Gambusia affinis ve Gambusia holbrooki türleri tüm dünyada sivrisinek balıkları olarak bilinmektedir. $\mathrm{Bu}$ çalışmada, sıklıkla karıştırıldıklarından, ayrıca biyolojik ve morfolojik açıdan birbirlerine benzemelerinden dolayı, her iki tür beraber değerlendirilmiştir. 1900'lü yılların başından itibaren sıtma hastalığına karşı sürdürülen biyolojik mücadeledeki yaygın kullanımları ve sahip oldukları yüksek yaşam toleranslarına bağlı olarak günümüzde dünya üzerindeki pek çok su kaynağında dağılım göstermektedirler. Bu türler hakkında yapılan bazı bilimsel çalışmalar, sivrisinek balıklarının dünyadaki yaygın kanının aksine ekosisteme zararsız türler olmadıklarını göstermiştir. Sivrisinek balıkları, ekosistem paylaşımında bulundukları diğer türleri, özellikle onların yumurta ve larvalarını yüksek miktarlarda tüketmek ve besin rekabetine girmek sureti ile tehdit edebilmektedir. Her iki tür de Türkiye tatlı sularından bilinmektedir. Türkiye'de pek çok endemik balık türü bulunması sebebi ile sivrisinek balıkları biyolojik çeşitlilik açısından büyük bir tehdittir. Türkiye'de sivrisinek balıklarının taşınması ve aşılanması resmî kurumlar tarafindan yasaklanmıştır.

Anahtar kelimeler: Gambusia affinis, Gambusia holbrooki, istilacı tür, ekolojik etki, endemik tür.
MAKALE BILGISI

\section{DERLEME}

$\begin{array}{lll}\text { Geliş } & : 26.07 .2016 \\ \text { Düzeltme } & : 22.02 .2017 \\ \text { Kabul } & : 27.03 .2017 \\ \text { Yayım } & : 24.04 .2017\end{array}$

DOI: 10.17216/LimnoFish.300927

* SORUMLU YAZAR

irmak.kurtul@ege.edu.tr

Tel: +90 2323111732

The Features, Current Status and Ecological Risks of Invasive Gambusia Species (Gambusia holbrooki ve G. affinis) in Turkey

Abstract: In this study, it is presented systematic place, distributions in Turkey, morphological characteristics, ecological features, habitat and feeding preferences, reproductive characteristics of two mosquitofishes, which are considered as a threat especially for endemic species' persistence. Gambusia affinis and Gambusia holbrooki are known as mosquitofishes all over the world. Because of these two species are constantly confused, also they have similar biological and morphological features, both species were examined together, in this study. Because they are used in biological control fruquently since the beginning of the $20^{\text {th }}$ century and have high environmental adaptability, they are distributed in many water bodies in the world today. Some scientific studies demonstrated that unlike the common sense they are not harmless to the ecosystem. Mosquitofishes threat the other species, which are living together at the same ecosystem, especially by predating on their eggs and larvae, and competing on habitat and space. Both species are also known to exist in Turkish inland waters. Since there are many endemic fishes belonging to Turkey, mosquitofish is a major threat for the biological diversity. Introduction of mosquitofish to water resources in Turkey has banned by official statement issued by institutions.

Keywords: Gambusia affinis, Gambusia holbrooki, invasive species, ecological impact, endemic species.

Alıntılama

Kurtul I, Sarı HM. 2017. İstilacı Gambusia Türlerinin (Gambusia holbrooki ve G. affinis) Özellikleri, Türkiye'deki Durumları ve Oluşturdukları Ekolojik Riskler. LimnoFish. 3(1):51-60. doi: 10.17216/LimnoFish.300927

\section{Giriş}

Doğal olarak yaşamlarını sürdürdükleri habitatlardan başka habitatlara bilinen ya da bilinmeyen bir yolla, istemli ya da istemsiz olarak taşınan ve taşındıkları habitatlarda bazı olumsuz etkiler yaratan türlere istilacı türler denilmektedir (Özdemir ve Ceylan 2007). Biyolojik çeşitliliğin devamı açısından büyük bir tehdit oluşturmakta 
olan biyolojik istila, özellikle tatlı su ekosistemlerinin dengesi için önemli bir risktir (Towsend 2003). İstilacılar, ekosistem içerisinde yerel ve endemik olarak dağılım gösteren diğer türler üzerinde pek çok olumsuz etki yaratabilmektedir. İstilacı türleri habitatları için tehdit hâline getiren özelliklerinin başında farklı çevre koşullarına uyum gösterebilmeleri, oldukça başarılı üreme stratejileri geliştirmiş olmaları ve farklı besinler ile beslenebilme yetenekleri gelmektedir (Carman vd. 2006). Gambusia affinis ve Gambusia holbrooki türleri de sahip oldukları bu özellikler ile giriş yaptıkları tatlı su kaynaklarında büyük populasyonlar oluşturabilmekte, ekosistem faunasının diğer üyeleri için çeşitli riskler yaratabilmektedir. Gambusia cinsi üyeleri, çoğunlukla tatlı sularda dağılım gösterirler; ancak acisularda ve tuzlu sularda yaşayan üyeleri de mevcuttur (Zarev 2012). Anavatanları Kuzey Amerika'da bulunan Meksika, Alabama ve Teksas'tır. Tüm dünyaya bu bölgeden insan eli ile dağılım göstermişlerdir (Lloyd ve Tomasov 1985; Moyle 2002).

Çalışmada, yarattıkları besin ve habitat kullanım rekabeti ile birlikte, habitat paylaşımında bulundukları türlerin yumurta ve larvalarını da tüketen bu iki sivrisinek balığı türünün sistematik özellikleri, Türkiye'deki dağılımları, morfolojik ve ekolojik özellikleri, habitat ve besin tercihleri ile üreme özellikleri hakkında bazı bilgiler verilmesi amaçlanmıştır.

\section{Sistematik Özellikleri}

Sivrisinek balıkları Cyprinodontiformes (Dişli sazancıklar) takımının Poeciliidae familyasına aittir. $\mathrm{Bu}$ familya, sivrisinek balıkları ile birlikte lepistes, pilati, moli ve k1lıçkuyruk gibi içerisinde dünyaca tanınmış pek çok balık türünü barındırır. Gambusia genusunun doğal dağılım alanı Kuzey Amerika'dır (Lloyd ve Tomasov 1985; Lloyd 1987) ve bu alan içerisinde 45 tür (Çizelge 1) ile temsil edilen genus üyelerinin bazıları tüm dünyaya dağılmıştır (Froese ve Pauly 2010). Genus içerisinde dünyada en çok tanınan türler, dünyada "sivrisinek balıkları" olarak bilinen G. affinis ve G. holbrooki türleridir.

\section{Taksonomik Kargaşa}

Wooten vd. (1988) tarafindan yapilan genetik çalışmaya kadar, alt tür ( $G$. affinis affinis ve $G$. affinis holbrooki) seviyesinde kabul edilen $G$. affinis ve G. holbrooki, küçük olmalarının yanında biyolojik, morfometrik ve meristik açıdan birbirlerine oldukça benzediklerinden günümüz çalışmalarında dahi sıklıkla karıştırılmaktadır. Bu nedenden dolayı, iki türün tespit edilmesinde ve sistematik açıdan kategorize edilmesinde 150 yıldan fazla süredir sorunlar yaşanmaktadır (Walters ve Freeman 2000; Pyke 2005).

Araştırıcıların büyük bir kısmı, genetik çalışmalar yardımı ile tür tayini yapma şansı bulamadığından, bu iki türü tayin ederken dorsal ve anal yüzgeç 1şın sayılarındaki farklılıktan yararlanmaya çalışmışlardır. Ancak dorsal ve anal yüzgeçlerinin 1şın sayılarının net olmayışı, bu türleri birbirinden tam olarak ayırmaya firsat vermemektedir. Walters ve Freeman (2000), çeşitli araştırıcılara göre G. affinis ve G. holbrooki türlerinin dorsal yüzgeç ve anal yüzgeç 1 şın sayılarını vermiştir (Çizelge 2). Araştırıcılara göre her iki türün de dorsal yüzgeç 1şını sayısı 6-7(8) arasında iken anal yüzgeç 1şını sayıları (8)910(12) arasında değişmektedir.

Dorsal ve anal yüzgeç 1şını sayılarının bu denli yakın olması ve bu konuda tam olarak bir netlik sağlanamaması sebebi ile, bu iki türü birbirinden ayırabilmek adına ilk olarak Berg (1949) tarafindan gonopodyum yapilar1 kullanılmaya başlanmış, Rauchenberger (1989) ise 1 ş1k mikroskobu altında yetişkin erkek bireylerin gonopodyumlarını (Şekil 1) incelemiş ve aradaki farklıları ortaya koymuştur. Sonuç olarak G. holbrooki türünün gonopodyumunun posterior kısmında ufak çentikler bulunduğu (Şekil 1b), G. affinis türünde ise bu çentiklerin bulunmadığı (Şekil 1c) belirtilmiştir (Özuluğ vd. 2007). Bu iki türün morfolojik ve anatomik açıdan bu denli benzer olmaları sebebiyle bugüne dek yapılmış pek çok çalışmada karıştırıldıkları, hatta güncel çalışmalarda dahi karıştırılmaya devam edildikleri tahmin edilmektedir (Pyke 2005).

Türkiye su kaynaklarında sivrisinek balıkları hakkında bugüne dek yapılmış çalışmalara bakıldığında, çalışmaların büyük bir çoğunluğunda G. affinis türü (Geldiay ve Balık 1996; Bahadıroğlu ve Büyükçapar 1997; Öztürk ve İkiz 2003) bildirilmiş olmakla birlikte, son dönem çalışmalarının önemli bir kısmında $G$. holbrooki türü (Kuru 2004; Tarkan vd. 2006; Ergüden 2013; Özuluğ vd. 2013) rapor edilmiştir. 
Çizelge 1. Gambusia cinsine ait türler (Froese ve Pauly 2010’den).

\begin{tabular}{|c|c|c|c|c|}
\hline \multicolumn{5}{|c|}{ Tür Adları } \\
\hline G. affinis & G. dominicensis & G. hurtadoi & G. myersi & G. rhizophorae \\
\hline G. alvarezi & G. echeagarayi & G. krumholzi & G. nicaraguensis & G. senilis \\
\hline G. amistadensis & G. eurystoma & G. lemaitrei & G. nobilis & G. sexradiata \\
\hline G. atrora & G. gaigei & G. longispinis & G. раписо & G. speciosa \\
\hline G. aurata & G. geiseri & G. luma & G. pseudopunctata & G. vittata \\
\hline G. baracoana & G. georgei & G. manni & G. punctata & G. wrayi \\
\hline G. beebei & G. heterochir & G. marshi & G. puncticulata & G. xanthosoma \\
\hline G. bucheri & G. hispaniolae & G. melapleura & G. quadruncus & G. yucatana \\
\hline G. clarkhubbsi & G. holbrooki & G. monticola & G. regani & G. zarskei \\
\hline
\end{tabular}

Çizelge 2. Bazı araştırıcılara göre G. affinis ve G. holbrooki’nin dorsal ve anal yüzgeç ışını sayıları (Walters ve Freeman 2000'dan).

\begin{tabular}{lcccc}
\hline \multirow{2}{*}{ Kaynakça } & \multicolumn{2}{c}{ G. affinis } & \multicolumn{2}{c}{ G. holbrooki } \\
\cline { 2 - 5 } & Dorsal & Anal & Dorsal & Anal \\
\hline Regan (1913) & $6-7$ & $10-11$ & 8 & 10 \\
Hubbs (1926) & $7-8$ & - & $6-8$ & $9-10$ \\
Hubbs ve Lagler (1964) & 6 & 9 & 7 & 10 \\
Lydeard vd. (1991) & 6 & 9 & 7 & 10 \\
Page ve Burr (1991) & 6 & - & 7 & - \\
Etnier ve Starnes (1993) & 7 & 10 & 8 & 10 \\
Angus ve Howell (1996) & 6 & 9 & 7 & 10 \\
Mettee vd. (1996) & 6 & 9 & 8 & 10 \\
Walters ve Freeman (2000) & $6-7$ & 10 & 8 & $11-12$ \\
\hline
\end{tabular}
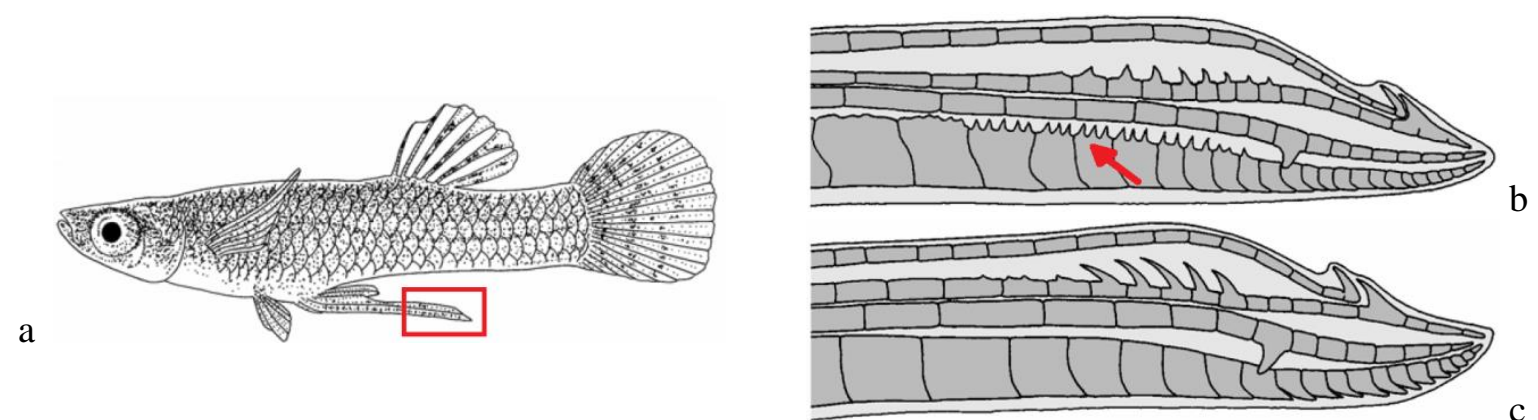

Şekil 1. a) Gambusia gonopodyum. b) G. holbrooki gonopodyum ve çentikleri. c) G. affinis gonopodyum (Veenvliet 2007).

\section{Ekolojik Özellikleri}

G. affinis ve G. holbrooki türlerinin $4-42^{\circ} \mathrm{C}$ gibi oldukça geniş bir sicaklık aralığında yaşayabildiği ifade edilmekle birlikte, bu türlerin optimum su sicaklığının $31-35{ }^{\circ} \mathrm{C}$ arasında olduğu belirtilmiştir (Pyke 2005). Bu türler yaşam alanı olarak genellikle tatlı suları tercih ederler, ancak G. holbrooki türünün $\% 23$ tuzluluğa sahip bir su kaynağında da populasyon oluşturabildiği gözlenmiştir (Alcaraz ve GarciaBerthou 2007). Tolerans gösterebildikleri $\mathrm{pH}$ değeri ise 4,7-10,2 arasında olmak üzere oldukça 
geniş bir aralıkta değişmektedir (Walton vd. 2012).

Sivrisinek balıkları oldukça güçlü bir adaptasyon yeteneğine sahip olduklarından çevresel değişkenlerin varyasyon göstermesine yüksek tolerans gösterebilirler. Bu nedenle farklı su kalite sınıflarında yaşayabilirler. Göller, göletler, lagünler, kuyular ve bataklıklar başlıca yaşam alanları arasındadır. Akarsuların mansap bölgelerinde yaşayıp, su akışının oldukça yavaşladığı, bol vejetasyonlu kıyısal bölgelerini tercih ederler (Rupp 1997). Yaşadıkları su kaynaklarının sığ yerlerini tercih ederler. Bu tip sığ alanlar, bol besin ve saklanma açısından uygun ortam yarattığı için balıklar tarafindan tercih edilmektedir (Zarev 2012).

\section{Besin Tercihleri}

Sivrisinek balıkları karnivor olup, oldukça geniş bir yelpazede beslenmektedirler (Ergüden 2013). Küçük böcekler, zooplankton, zoobentoz tüketen bu türler, ekosistem paylaşımında bulunduğu diğer türlerin yumurta ve larvalarını da tüketebilmektedir (Goodsell ve Kats 1999; Özuluğ vd. 2013).

Sivrisinek balıklarının beslenme rejimi hakkında dünyada yapılmış bazı çalışmalar bulunmaktadır. Sokolov ve Chvaliova (1936) Türkmenistan'da yaptıkları çalışmada G. affinis türünün anofel, Cladocera, Coleoptera, Rotatoria, Chironomidae tükettiğini; Arthington (1989) $G$. holbrooki türünün çeşitli omurgasızları ve özellikle karasal ve sucul böcekleri tükettiğini; Garcia-Berthou (1999) G. holbrooki türünün ağırlıklı olarak böcek ve Crustacea tükettiğini, sivrisinek larvasını ise çok az miktarda tükettiğini; Gkenas vd. (2012) Yunanistan'da yaptıkları çalışmada $G$. holbrooki türünün
Crustacea, Diptera, Coleptera, Hymenoptera, Hemiptera tükettiğini belirtmiştir.

Türkiye'de ise bu türlerin mide içerikleri hakkında yapılmış çalışmalar oldukça az sayıdadır. Bunlardan Seyhan Baraj Gölü'nde (Adana) yapılmış olan bir çalışmada G. holbrooki türünün \%53,90 oranında Diptera (larvas1 ve pupas1), \%14,70 oranında balık yumurtas1, $\% 13,72$ oranında zooplankton (Cladocera, Copepoda), \%1 oranında diğer böcek grupları (Coleoptera, Hemiptera, Hymenoptera, Trichoptera, Plecoptera) ile beslendikleri ve \%3,92 oranında da kendi türünden olan bireyleri tükettikleri (kanibalizm) tespit edilmiştir (Ergüden 2013).

\section{Büyüme Özellikleri}

Dünya ve Türkiye genelinde bu türlerin büyümeleri ile ilgili yapılmış çok az çalışma bulunmaktadır. Bazı biyolojik çalışmalardaki yaş dağılımları Çizelge 3'te verilmiştir. Yapılan çalışmalarda her iki türün de en çok 2 yaşına kadar yaşayabildiği, ancak büyük bir çoğunluğunun 1 yaşın üzerine çıkamadığı belirtilmiştir.

Yapılan çalışmalarda, herhangi bir bölgede, herhangi bir zamanda bir populasyon içerisinde bulunan dişi sivrisinek balığı sayısının, erkek sayısından neredeyse her zaman fazla olduğu, aynı zamanda dişi bireylerin erkek bireylerden daha uzun yaşayıp, daha uzun boya ve daha fazla vücut ağırlı̆̆ına sahip olduğu tespit edilmiştir (Öztürk ve İkiz 2003; Ergüden ve Ergüden 2008; Zarev 2012). Bu çalışmalar içerisinde Rupite Kaplıcası (Bulgaristan)'ndaki çalışma hariç, tüm çalışmalarda dişi sayısı erkek sayısından daima fazla olarak bulunmuştur (Zarev 2012). Yapılan çalışmalardaki dişi-erkek oranları verilmiştir (Çizelge 4).

Çizelge 3. Gambusia türleri üzerine yapılan bazı çalışmalardaki yaş dağılım yüzdeleri.

\begin{tabular}{|c|c|c|c|}
\hline \multirow[t]{2}{*}{ Lokalite } & \multicolumn{3}{|c|}{ Yaşlar } \\
\hline & $0+$ & $1+$ & $2+$ \\
\hline Akgöl, Fethiye (Öztürk ve İkiz 2003) ${ }^{\mathrm{a}}$ & 97,59 & 2,41 & - \\
\hline Dalaman ilçesi bataklıkları (Öztürk ve İkiz 2004) ${ }^{\text {a }}$ & 99,71 & 0,29 & - \\
\hline Ortaca ilçesi bataklıkları (Öztürk ve İkiz 2004) ${ }^{a}$ & 94,37 & 5,63 & - \\
\hline Seyhan Baraj Gölü, Adana (Ergüden ve Ergüden 2008) a & 41,72 & 38,30 & 13,54 \\
\hline Seyhan Baraj Gölü, Adana (Ergüden 2013) & 9,48 & 45,14 & 45,38 \\
\hline Guadalguivir Nehri, İspanya (Fernández-Delgado 1989)a & 50,56 & 49,44 & - \\
\hline
\end{tabular}

a: G. affinis, b: G. holbrooki. 
Çizelge 4. Farklı habitatlarda bulunan Gambusia populasyonlarının dişi-erkek oranları.

\begin{tabular}{|c|c|c|c|c|}
\hline Lokalite & $\mathrm{n}$ & $\begin{array}{l}\bar{\partial} \hat{} \\
(\%)\end{array}$ & $\begin{array}{l}q 0 \\
(\%)\end{array}$ & $\begin{array}{l}\text { Eşey } \\
\text { Oranı }\end{array}$ \\
\hline Akgöl, Fethiye (Öztürk ve İkiz 2003)a & 705 & 18,58 & 81,42 & $4: 1$ \\
\hline Dalaman ilçesi bataklıkları (Öztürk ve İkiz 2004)a & 682 & 28,45 & 71,55 & $3: 1$ \\
\hline Ortaca ilçesi bataklıkları (Öztürk ve İkiz 2004)a & 639 & 29,58 & 70,42 & $3: 1$ \\
\hline Seyhan Baraj Gölü, Adana (Ergüden ve Ergüden 2008)a & 224 & 38,40 & 61,60 & $2: 1$ \\
\hline Seyhan Baraj Gölü, Adana (Ergüden 2013) ${ }^{\mathrm{b}}$ & 1582 & 48,80 & 51,20 & $1: 1$ \\
\hline Dolni Bogrov Gölü, Bulgaristan (Zarev 2012) ${ }^{\mathrm{b}}$ & 213 & 30,52 & 69,48 & $2: 1$ \\
\hline Meriç Nehri (Maritza River), Bulgaristan (Zarev 2012) & 23 & 34,78 & 65,22 & $2: 1$ \\
\hline Ognyanovo Rezervuarı, Bulgaristan (Zarev 2012) ${ }^{\mathrm{b}}$ & 77 & 20,78 & 79,22 & $4: 1$ \\
\hline Pancharevo Rezervuarı, Bulgaristan (Zarev 2012) ${ }^{\mathrm{b}}$ & 564 & 32,10 & 67,90 & $2: 1$ \\
\hline Potamyata Nehri, Bulgaristan (Zarev 2012) ${ }^{\mathrm{b}}$ & 59 & 23,73 & 76,27 & $3: 1$ \\
\hline Rupite Kaplıcası, Bulgaristan (Zarev 2012) & 148 & 52,70 & 47,29 & $1: 1$ \\
\hline Tunca Nehri (Tundzha River), Bulgaristan (Zarev 2012) & 183 & 39,34 & 60,65 & $2: 1$ \\
\hline
\end{tabular}

a: G. affinis, b: G. holbrooki.

\section{Üreme Özellikleri}

$\mathrm{Bu}$ türler, $12^{\circ} \mathrm{C}$ olan su sicaklıklarında üremeye başlar. Optimum üreme sıcaklıkları ise $25^{\circ} \mathrm{C}$ olarak belirtilmiştir (Geldiay ve Balık 1996). Üremeleri tropikal bölgelerde genelde bütün bir yıl boyunca olurken, kışların serin veya soğuk olduğu yerlerde yalnızca yaz aylarında gerçekleşir. Canlı doğuran bu türlerin dişileri ortam şartları uygun olduğunda 3-4 haftada bir doğum yaparlar. 1 yaşına kadar olan dişileri bir batında ortalama 30 yumurtaya sahip iken, 1 yaşını doldurmuş dişileri ortalama 70 yumurtaya sahip olabilir (Öztürk ve İkiz 2004). Bu türlerin 20-30 gün boyunca süren doğurma periyotları vardır. Sivrisinek balıkları yavrulama alanı olarak çakı1lı habitatları tercih ederler ve böylece yavrularını hem predatör etkilerinden hem de kanibalizmden koruyarak onların yaşama şanslarını arttırırlar.

\section{Türlerin Biyolojik Mücadeledeki Yerleri}

Ekosistem işleyişine, canlılara, insan sağlığına ya da ekonomiye zararlı canlıların doğal düşmanları yardımıyla kontrol altına alınması işlemi biyolojik mücadele olarak bilinmektedir. Son yüzyıl içinde tatlı sularda kullanılan biyolojik ajanlara verilebilecek en iyi örneklerden biri; ara konakçıları anofel cinsi sivrisinekler olan sitma hastalığının kontrolü için tüm dünyaya aşılanmış sivrisinek balıklarıdır (Kumar ve Hwang 2006). Pek çok uygarlığın çöküşüne sebep olmuş bu hastalığa karşı bir yandan aş1 geliştirme çalışmaları sürdürülürken, bir yandan da sivrisinek balıklarının sivrisinek larvaları üzerinden beslendikleri tespit edilmiş ve bu özellikleri yardımıyla sitma hastalığının kontrol altına alınabileceği düşünülmüştür. Bu amaçla sivrisinek balıklarına 1800 'lü yılların sonundan itibaren sıtmaya karşı biyolojik ajan olarak dünyanın pek çok ülkesinde rol verilmeye başlanmıştır (Walters ve Freeman 2000). İlk sivrisinek balığı aşılaması Teksas'tan Hawai'ye yapılmış, Avrupa'da ilk aşılama ise 1921 yılında İtalya'ya, ardından da İspanya'ya gerçekleştirilmiş, Bulgaristan'a ise 1924 yılında aşılama yapılmıştır (Zarev 2012). Sivrisinek balıkları, sularımıza aşılaması yapılan ilk yabancı tür (İnnal ve Erk'akan 2006) olmakla beraber, bu balıkların Türkiye'ye ilk defa Fransızlar tarafindan, sivrisineklerle biyolojik mücadele yapmak amaciyla Avrupa ülkelerinden getirilip Amik Gölü'ne aşılandığ 1 belirtilmektedir (Geldiay ve Balık 1996). Ancak getirilişi ile ilgili herhangi bir resmî kayda ulaşılamamıştır. Bu balıklar resmî olarak ilk kez 1960 yılında Çukurova Bölgesi'ne aşılanmıș (Bahadıroğlu ve Büyükçapar 1997), sonraki dönemlerde Sitma Mücadele Müdürlükleri, Devlet Su İşleri ve halk tarafından Türkiye'nin pek çok su kaynağına taşınmış, dayanıklılığı ve yüksek üreme kabiliyeti ile her gittiği bölgede önemli populasyonlar oluşturmuştur. Yapılan bilimsel çalışmalar, 
sivrisinek balıklarının Türkiye'deki dağılım alanlarının oldukça geniş olduğunu kanıtlamakla birlikte, Türkiye'de kaydının verildiği su kaynakları (Aras Nehri, Geldiay ve Balık 1996; Bafa Gölü, Sarı vd. 1999; Yuvarlakçay, Balık vd. 2005; Beyşehir Gölü, Yeğen vd. 2006; Afyon akarsuları, Yeğen vd. 2007; Eğirdir Gölü, Küçük vd. 2009; Taflan Deresi, Uğurlu ve Polat, 2007; Apolyont Gölü, Berber vd. 2011; Nizip Çayı, Birecikligil ve Çiçek 2011; Kırkgöz Deresi, Güçlü ve Küçük 2011; Marmara Gölü, İlhan ve Sarı 2013) dişında daha pek çok su kaynağında dağılım gösterdiği tahmin edilmektedir.

$\mathrm{Bu}$ balıkların sivrisinek larva ve pupalarını tüketiyor olmaları sebebi ile her ne kadar sitma hastalığına karşı biyolojik mücadelede kullanılabilecekleri düşünülmüş olsa da, yapılan çalışmalar türün bu konuda diğer pek çok yerli türe göre çok da anlamlı bir etkisinin olmadığını göstermiştir. Zira sivrisinek balıkları karnivor balıklardır. Dolayısı ile sadece sivrisinek larva ve pupalarını değil, ortamda bulunan diğer sucul organizmaları da sıklıkla tüketirler (Ergüden 2013); bu nedenle bu balıkların sıtmaya karşı sürdürülen biyolojik mücadelede habitatta bulunan yerel türlerden herhangi bir üstünlükleri bulunmamaktadır (Harrington ve Harrington 1961; Meisch 1985). Sivrisineklerle mücadelede ortamın yerli türlerine göre herhangi bir üstünlüğü bulunmayan bu türler, yapılan biyolojik mücadele çalışmalarının sonucu olarak, sahip oldukları yüksek yaşam toleransları sayesinde taşındıkları habitatlarda büyük populasyonlara sahip olmuşlardır (Garcia-Berthou vd. 2005).

\section{Türlerin Risk ve Etki Faktörleri}

Farkl1 karakterdeki sucul habitatlara uyum sağlama ve girdikleri ortamlarda çok kısa zamanda büyük populasyonlar oluşturabilme yeteneğine sahip sivrisinek balıkları, ekosistemlerde meydana getirdikleri pek çok negatif etkiden dolayı, dünyanın "en istilacı 100 türü” arasında yerini almıştır (ISSG 2013). Bununla birlikte, Tarkan vd. (2014) tarafindan Türkiye sularında dağılım gösteren 35 tür hakkında yapılan risk tarama çalışmasında (FISK: Fish Invasiveness Screening Kit), G. affinis ve $G$. holbrooki türlerinin de istilacılık özellikleri değerlendirilmiş, çalışma sonucunda her iki türün de risk skorunun oldukça yüksek olduğu tespit edilmiştir. Dünyanın birçok yerinde ekolojik zararlarından bahsedilen sivrisinek balıklarının, tatlı su balık endemizm oranının bu denli yüksek olduğu, bu mevcut endemik türlerin büyük çoğunluğunun da "dar endemik" (dağılımı oldukça sınırlı olan) özellik gösterdiği Türkiye'de, birçok tatlı su habitatında bulunmaları ve kontrol edilemeyen taşınışları endemik türlerin varlığını tehdit etmektedir.

Sivrisinek balıklarının en önemli olumsuz etki mekanizması, bu balıkların ekosistem paylaşımında bulunduğu diğer türlerin besinlerine ortak olurken, aynı zamanda onların yumurtalarını ve larvalarını da tüketebiliyor olmalarıdır (Goodsell ve Kats 1999; Özuluğ vd. 2013).

$\mathrm{Bu}$ balıkların diğer olumsuz etki mekanizmaları arasında diğer türlerle rekabet, üreme aktivitelerini sinırlama ve saldırgan hareketler ile ekosistemin diğer canlı öğeleri üzerinde çeşitli olumsuz etkiler yaratmaları da vardır. Bunlara ek olarak; sivrisinek balıklarının beslenme tercihlerinin başında zooplanktonun gelmesi ve türün zaman zaman zooplankton üzerindeki predasyon baskısıyla fitoplanktonun aşırı çoğalmasına sebep olabilmesi de bir diğer olumsuz etki mekanizmasıdır (Pyke 2008).

\section{Türlerin Mevzuattaki Yerleri}

Türkiye, biyolojik çeşitliliği koruma kapsamında uluslararası olarak bazı anlaşmalar imzalamıştır. İstilacı özellikte oldukları yapılan bilimsel çalışmalar ile kanıtlanmış olan sivrisinek balıklarının su kaynaklarına aşılanması, imzalanan bu uluslararası anlaşmalar nedeniyle bağlayıcıdır.

Türkiye'nin de akit taraflarından biri olduğu, 1992'de imzalanan Birleşmiş Milletler Biyolojik Çeşitlilik Sözleşmesi'nin "In-Situ Koruma” isimli 8'nci maddesinin h fikrasında: "Ekosistemleri, yaşam ortamlarını veya türleri tehdit eden yabancı türlerin girişini engelleyecek, bu türleri denetim altına alacak veya yok edecektir." hükmü ile yine aynı maddenin $\mathrm{k}$ fikrasında: "Tehdit altındaki türlerin ve populasyonların korunması için gerekli mevzuatı ve/veya düzenleyici diğer hükümleri gelistirecek veya idame ettirecektir." hükümleri bulunmaktadır (Resmî Gazete 1997).

Ayrıca Türkiye'nin imzaladığı Avrupa yaban hayatı ve yaşam ortamlarının korunmasını hedefleyen Bern Sözleşmesi (9 Ocak 1984'te taraf olunmuş), nesli tehlike altında bulunan türlerin ticaretini düzenleyen CITES sözleşmesi (22 Aralık 1996'da taraf olunmuş), özellikle su kuşları yaşama alanı olarak uluslararası öneme sahip sulak alanların korunmasını amaçlayan Ramsar Sözleşmesi (30 Aralık 1993'te taraf 
olunmuş) gibi uluslararası sözleşmeler de bulunmaktadır.

Bununla birlikte Türkiye'nin taraf olduğu Gıda ve Tarım Örgütü (FAO) Sorumlu Balıkçılık İlkeleri (1995), Yabani Hayvan ve Bitki Türleri ile Doğal Yaşam Alanlarının Korunması Direktifi (Habitat Direktifi- 92/43/AET), Yabanc1 ve Yerelde Olmayan Türlerin $\mathrm{Su}$ Ürünleri Yetiştiriciliğinde Kullanılması Hakkında Konsey Tüzüğü (708/2007/EC), İstilac1, Yabanc1 Türlerin Tanıtımı, Yayılmasının Önlenmesi ve Yönetimine İlişkin Avrupa Parlamentosu ve Konsey Tüzüğü (2013/0307/COD) gibi bazı bildirge ve tüzüklerde de yabanc1/istilacı türlere karşı koruyucu maddeler içeren yükümlülükler bulunmaktadır (Atalay ve Toslak 2013).

Sivrisinek balıkları, Su Ürünleri Yönetmeliği'nin 1995 yılında yayınlanan 3/2 nolu tebliğinin 8'nci maddesine göre, iç sularımızda ekolojik açıdan potansiyel zararlı balıklar arasinda gösterilmekte ve haklarında "Sivrisineklerle mücadelede kullanılan ve zararsız olduğu düşünülen bu balık türü, bırakıldiğı sularda bazı balık türlerinin yumurtaların yiyerek zararl olabilmektedir. Yerleştiği habitattan temizlenmesi çok zordur." denilmektedir (Resmî Gazete 1995).

Türkiye'de yapılan tüm balıklandırma çalışmaları, 1380 sayılı Su Ürünleri Kanunu'nun 13 ve 23'üncü maddeleri ile $\mathrm{Su}$ Ürünleri Yönetmeliği'nin 16'ncı maddesi gereğince Gıda Tarım ve Hayvancılık Bakanlığı'nın sorumluluğunda olmakla birlikte, Orman ve $\mathrm{Su}$ İşleri Bakanlığı'nın da balıklandırma çalışmaları ile ilgili bazı yetkileri bulunmaktadır. Bunlarla birlikte, balık aşılama için yetkisi bulunmayan kurumlar ya da kişiler, farklı bilgi kaynaklarından elde ettikleri bilgilerle, yöresel olarak sivrisinekler veya diğer dipter türleri ile mücadele için, bu balıkları değişik su kaynaklarından toplayarak; olas1 bu etkilerine, imzalanan sözleşmelere, tüzüklere ve yayınlanan bu tebliğlere karşın hâlâ Türkiye'nin çeşitli su kaynaklarına aşılayabilmektedir.

\section{Sonuç}

Günümüzde sivrisinek balıklarının, sivrisinek kontrolü üzerindeki başarısı, yapılan bilimsel çalışmalardaki yetersizlikler sebebiyle hâlâ tartışmalıdır. Sıtma tedavisinde kullanılan kinin maddesinin karaciğer hastalıklarına yol açtığı (Kouyoumdjian vd. 2009) tespit edildikten sonra, sıtmaya karşı mücadelede alternatif bir yöntem aranmış ve çözüm olarak bu balıklar dünyanın çeşitli yerlerine sivrisineklerle mücadele amaçlı aşılanmaya başlanmıştır. Sivrisinek kontrolü ile ilgilenenler bu türlerin çeşitli su kaynaklarına aşılanmasını tavsiye ederken; doğa bilimciler bu türlerin farklı habitatlara aşılanmasına türlerin tespit edilen zararlı etkileri ve olası zararlı etkileri nedeniyle karşı çıkmaktadırlar (Crivelli 1995). Bu balıklar tam olarak derecesi belli olmasa da sivrisinek larvalarını tüketiyor olmaları sebebi ile insan sağlığı açısından bazı olumlu etkiler gösterebiliyorken, biyolojik çeşitlilik, endemik türler ve ekonomi açısından bazı olumsuz etkiler yaratabilmektedirler. Endemik türlerin, ülkelerin sahip oldukları biyolojik zenginlikler açısından ne denli önemli olduğunun çok daha iyi anlaşılmaya başlandığı son yüzyılda, sivrisinek balıkları gibi istilacı özellik gösteren türlerin özellikle endemik türler üzerinde yaratabileceği negatif etkileri önleyebilmek adına kapsamlı önlemler alınması gerekmektedir.

Bir sucul kaynaktan başka bir sucul kaynağa geçen balık türü, yeni sucul ortamında birtakım olumsuz çevre koşulları ile karşılaşır. Türlerin farklı çevre şartlarına karşı adaptasyon yetenekleri birbirinden farklı olmakla birlikte, sivrisinek balıklarının sahip oldukları adaptasyon yeteneklerinden dolayı yeni habitatlardaki yaşama yüzdeleri yüksektir. Mücadeleci yanları kuvvetli olan bu gibi bazı türler, yeni aşılandıkları su ortamında kendilerini fazla zorlayan anormal şartlar yoksa populasyon oluşturma yoluna gidecek, başarılı olacak ve başarılı olduktan sonra o türü aşılandığı su kaynağından uzaklaştırmak neredeyse imkânsız bir hâl alacaktır.

Akvaryum ticareti yolu ile balıkların kıtalararası da dahil olmak üzere oldukça rahat pazarlandığ1 günümüz dünyasında, G. affinis ve G. holbrooki türleri dışında Gambusia genusuna ait olan başka bir türün sularımıza girip girmediği şüphelidir. Bununla birlikte Türkiye'de yapılan kontrolsüz balıklandırma çalışmaları ve bilinçsizce hareket eden kişiler nedeni ile aşılanan türlerin hangi su kaynaklarından getirildiği bilinemediğinden, sivrisinek balık türlerinin durumları henüz açıklığa kavuşturulamamıştır. $\mathrm{Bu}$ türlerle etkin ve doğru bir şekilde mücadele edebilmek, ancak doğru tür tanımlamaları ile mümkün olabilecektir.

Balıklandırma çalışmalarının olumsuz etkilerini en aza indirgeyebilmek açısından su kaynaklarına balık aşılaması yapılmadan önce, habitatın fiziksel ve kimyasal özelliklerinin incelenmesi, ekolojik nişler açısından ekosistem işleyişinin belirlenmesi, doğal türlerin risk 
durumlarının ortaya çıkarılması, suya aşılanacak türün biyo-ekolojisinin ve ekosistem içerisindeki yerinin belirlenmesi, aşılamanın ekosistem için getireceği fayda/zarar analizinin yapılması; habitata yabancı bir tür getirilmeden önce habitatın besin zincirinin belirlenmesi ve hedeflenen eylem doğrultusunda boş ekolojik nişin olup olmadığının ortaya koyulması gerekmektedir. Eğer boş niş yok ise bu eylemden kaçınılmalı ve yerel türün populasyonunun düzenli aralıklarla desteklenmesi yoluna gidilmelidir.

Bunun dışında Türkiye tatlı sularında $G$. affinis ve $G$. holbrooki türleri ile ilgili yapılan çalışmaların niteliği ve niceliği arttırılmalı, bu türlerin hem yerel hem de endemik türler üzerinde yarattığı etkiler tam olarak ortaya koyulmalıdır. Beslenme rejimleri detaylı olarak incelenmeli, özellikle türlerin sivrisinek larvaları üzerinde yarattıkları predasyonun derecesi ortaya koyulmalıdır. Buna ek olarak sivrisinek balıkları ile benzer beslenme rejimine sahip olan balık türlerinin de beslenme rejimleri incelenmeli, aradaki benzerlik ve farkl1liklar da belirlenmelidir. Yapılan balıklandırma eylemlerinin, sivrisinek larvaları ile beslenen diğer türler (küçük cyprinidler gibi) üzerindeki etkileri de incelenmelidir.

\section{Teşekkür}

$\mathrm{Bu}$ makale Ege Üniversitesi Fen Bilimleri Enstitüsü Su Ürünleri Temel Bilimler Anabilim Dalı'nda yürütülmekte olan "Türkiye'de Gambusia (Sivrisinek Balığı) Türlerinin Dağılımı ve Biyoekolojik Özelliklerinin İncelenmesi" başlıklı doktora tez çalışmasından üretilmiştir

\section{Kaynaklar}

Alcaraz C, Garcia-Berthou E. 2007. Life history variation of invasive mosquitofish (Gambusia holbrooki) along a salinity gradient. Biol Conserv. 139(1-2):83-92.

doi: 10.1016/j.biocon.2007.06.006

Arthington AH. 1989. Diet of G. affinis holbrooki, Xiphophorus helleri, X. maculatus and Poecilia reticulata (Pisces: Poeciliidae) in streams of southeastern Qeennsland, Australia. Asian Fish Sci. 2(2):193-212.

Atalay MA, Toslak C. 2013. Balıklandırma, yabancı ve istilacı balık türleri ile ilgili ulusal ve uluslararası mevzuat. J Fish Aquat Sci. 28(1):39-62.

Bahadıroğlu C, Büyükçapar HM. 1997. Sitma ile biyolojik mücadelede sivrisinek balıkları (Gambusia affinis, Baird ve Girard)'nın önemi. Ekoloji Çevre Dergisi. 22:34-36.
Balık S, Ustaoğlu MR, Sarı HM, İlhan A, Topkara ET. 2005. Yuvarlakçay (Köyceğiz, Muğla)'ın balık faunas1. Ege J Fish Aquat Sci. 22(1-2):221-223.

Berber S, Şaşı H, Topkara ET, Cengiz Ö. 2011. Apolyont Gölü (Bursa) balı faunasının belirlenmesi. J Fish Aquat Sci. 26(1):27-55.

Berg LS. 1965. Freshwater Fishes of the U.S.S.R. and Adjacent Countries. Volume 3, $4^{\text {th }}$ Edition. Jerusalem: Israel Program for Scientific Translations Ltd. $510 \mathrm{~s}$.

Birecikligil S, Çiçek E. 2011. Gaziantep ili sınırları içindeki Fırat ve Asi Havzası akarsuları balık faunas1. BİBAD. 4(2):29-34.

Carman SM, Janssen J, Jude DJ, Berg MB. 2006. Diel interactions between prey behaviour and feeding in an invasive fish, the round goby, in a North American river. Freshwater Biol. 51(4):742-755. doi: 10.1111/j.1365-2427.2006.01527.x

Crivelli AJ. 1995. Are fish introductions a threat to endemic freshwater fishes in the northern Mediterranean Region?. Biol Conserv. 72(2):311319.

doi: 10.1016/0006-3207(94)00092-5

Ergüden SA, Ergüden D. 2008. A preliminary research on growth feature of the mosquitofish Gambusia affinis (Baird\&Girard, 1853) determined in Seyhan Dam Lake (Adana-Turkey). J Fish Sci. 2(3):312-320. doi: $10.3153 /$ jfscom.mug.200718

Ergüden SA. 2013. Age, growth, sex ratio and diet of eastern mosquitofish Gambusia holbrooki Girard, 1859 in Seyhan Dam Lake (Adana/Turkey). Iran J Fish Sci. 12 (1):204- 218.

Fernández-Delgado C. 1989. Life history patterns of the mosquito-fish Gambusia affinis, in the estuary of the Guadalquivir river of south-west Spain. Freshwater Biol. 22(3):395-404. doi: 10.1111/j.1365-2427.1989.tb01113.x

Froese R, Pauly D. Editors. 2010. FishBase. World Wide Web electronic publication; [Erişim tarihi: 02.02.2016]. Erişim Adresi: www.fishbase.org online version (01/2016).

Garcia-Berthou, E. 1999. Food of introduced mosquitofish: ontogenetic diet shift and prey selection. J Fish Biol. 55(1):135-147. doi: 10.1111/j.1095-8649.1999.tb00663.x

Garcia-Berthou E, Alcaraz C, Pou-Rovira Q, Zamora L, Coenders G, Feo C. 2005. Introduction pathways and establishment rates of invasive aquatic species in Europe. Can J Fish Aquat Sci. 62(2):453-463. doi: $10.1139 /$ f05-017

Geldiay R, Balık S. 1996. Türkiye Tatlısu Balıkları Kitabı. II. Baskı. İzmir: Ege Üniversitesi Basım Evi $532 \mathrm{~s}$.

Gkenas C, Oikonomou A, Economou A, Kiosse F, Leonardos I. 2012. Life history pattern and feeding habits of the invasive mosquitofish, Gambusia 
holbrooki, in Lake Pamvotis (NW Greece). J Biol Res. 17:121-136.

Goodsell JA, Kats LB. 1999. Effect of introduced mosquitofish on Pacific treefrogs and the role of alternative prey. Conserv Biol. 13(4):921-924. doi: 10.1046/j.1523-1739.1999.98237.x

Güçlü SS, Küçük F. 2011. Reproductive biology of Aphanius mento (Heckel in: Russegger 1843) (Osteichthyes: Cyprinodontidae) in Kurkgöz Spring (Antalya: Turkey). Turk J Fish Aquat Sci. 11(2):323-327. doi: 10.4194/trjfas.2011.0217

Harrington RW, Harrington ES. 1961. Food selection among fishes invading a high subtropical salt marsh: from onset of flooding through the progress of a mosquito brood. Ecology. 42(4):646-666. doi: $10.2307 / 1933496$

ISSG. 2013. Global Invasive Species Database (Invasive Species Specialist Group); [Erişim tarihi: 22.07.2016]. Erişim Adresi: http://www.iucngisd.org/gisd/100_worst.php

İlhan A, Sarı HM. 2013. Marmara Gölü balık faunası ve balıkçılık faaliyetleri. Ege J Fish Aqua Sci. 30(4):187-191. doi: 10.12714/egejfas.2013.30.04.08

Innal D, Erk'akan F. 2006. Effects of exotic and translocated fish species in the inland waters of Turkey. Rev Fish Biol Fisheries. 16(1):39-50. doi: 10.1007/s11160-006-9005-y

Kouyoumdjian M, Nagaoka MR, Loureiro-Silva MR, Borges DR. 2009. Portal hypertensive response to kinin. An Acad Bras Cienc. 81(3):431-442.

Kumar R, Hwang JS. 2006. Larvicidal efficiency of aquatic predators: a perspective for mosquito biocontrol. Zoolog Stud. 45(4):447-466.

Kuru M. 2004. Türkiye iç su balıklarının son sistematik durumu. Gazi Univ J Gazi Edu Fac. 24(3):1-21.

Küçük F, Sarı HM, Demir O, Gülle İ. 2009. Review of the ichthyofaunal changes in Lake Eğirdir between 1915 and 2007. Turk J Zool. 33:277-286. doi: 10.3906/zoo-0811-16

Lloyd LN, Tomasow JF. 1985. Taxonomic status of the mosquitofish Gambusia affinis (Poeciliidae), in Australia. Aust J Mar Freshw Res. 36(3):447-451. doi: 10.1071/MF9850447

Lloyd L. 1987. An alternative to insect control by "mosquitofish" Gambusia affinis. In: TD St. George, BH Kay and J Blok, editors. Proceedings 4th Symposium on Arbovirus Research. Australia: Q.I.M.R. Brisbane. s. 156-163.

Meisch MV. 1985. Gambusia affinis affinis. In: H. C. Chapman, editor. Biological control of mosquitoes. Fresno, CA.: Am. Mosq Control Assoc. s. 3-16

Moyle PB. 2002. Inland Fishes of California. Revised and expanded. Berkeley: University of California Press. 502 s.
Özdemir G, Ceylan B. 2007. Biyolojik istila ve Karadeniz'deki istilacı türler. SÜMAE Yunus Arş Bül. Say1:3:1-5.

Öztürk Ş, İkiz R. 2003. Akgöl (Fethiye - Muğla) sivrisinek balığ Gambusia affinis (Baird \& Girard, 1853) populasyonunun bazı biyolojik özellikleri. Turk J Vet Anim Sci. 27(4):911-915.

Öztürk Ş, İkiz R. 2004. Some biological properties of mosquitofish populations (Gambusia affinis) living in inland waters of the Western Mediterranean region of Turkey. Turk J Vet Anim Sci. 28:355-361.

Özuluğ M, Tarkan AS, Gaygusuz Ö, Gürsoy Ç. 2007. Two new records for the fish fauna of lake Sapanca basin (Sakarya, Turkey). J Fish Sci. 1(3):152-159. doi: 10.3153/jfscom.2007018

Özuluğ M, Saç G, Gaygusuz Ö. 2013. İstilacı özellikteki Gambusia holbrooki, Carassius gibelio ve Pseudorasbora parva (Teleostei) türleri için Türkiye'den yeni yayılım alanları. J Fish Aquat Sci. 28(1):1-22.

Pyke GH. 2005. A review of the biology of Gambusia affinis and G. holbrooki. Rev Fish Biol Fisher. 15:339-365. doi: $10.1007 / \mathrm{s} 11160-006-6394-\mathrm{x}$

Pyke GH. 2008. Plague minnow or mosquito fish? A review of the biology and impacts of introduced Gambusia species. Annu Rev Ecol Evol Syst. 39:171-191. doi: 10.1146/annurev.ecolsys.39.110707.173451

Rauchenberger M. 1989. Systematics and biogeography at the Genus Gambusia (Cyprinodontiformes: Poeciliidae). Newyork: The American Museum of Natural History Novitates $74 \mathrm{~s}$.

Resmî Gazete. 1995. Su Ürünleri Yönetmeliği. Resmî Gazete Sayıs1: 22223. Resmî Gazete Tarihi:10.03.1995; [Erişim tarihi: 21.07.2016]. Erişim Adresi: http://mevzuat.basbakanlik.gov.tr/Metin.Aspx?M evzuatKod=7.5.4988\&sourceXmlSearch $=\&$ Mevz uatIliski $=0$

Resmî Gazete. 1997. Biyolojik Çeşitlilik Sözleşmesi. Resmî Gazete Sayısı: 22860 Resmî Gazete Tarihi: 27.12.1996; [Erişim tarihi: 22.07.2016]. Erişim Adresi: http://www.unicankara.org.tr/doc_pdf/biyo.pdf

Rupp HR. 1997. Mosquito control with Gambusia affinis. J Am Mosquito Cont. 13(3):296.

Sarı HM, Balık S, Bilecenoğlu M, Türe G. 1999. Recent changes in the fish fauna of Lake Bafa, Aegean Region of Turkey. Zool Middle East. 18(1):67-76. doi: 10.1080/09397140.1999.10637783

Sokolov NP, Chvaliova MA. 1936. Nutrition of Gambusia affinis on the rica fields Turkestan. J Anim Ecol. 5(2):390-395. doi: $10.2307 / 1042$ 
Tarkan AS, Gaygusuz Ö, Acıpınar H, Gürsoy Ç, Özuluğ M. 2006. Length-weight relationship of fishes from the Marmara region (NW-Turkey). J Appl Ichthyol 22(4):271-273. doi: 10.1111/j.1439-0426.2006.00711.x

Tarkan AS, Ekmekçi G, Vilizzi L, Copp GH. 2014. Risk screening of non-native freshwater fishes at the frontier between Asia and Europe: first application in Turkey of the fish invasiveness screening kit. J Appl Ichthyol. 30(2):392-398. doi: 10.1111/jai.12389

Towsend CR. 2003. Individual population community and ecosystem consequences of a fish invader in New Zealand streams. Conserv Biol. 17(1):38-47. doi: 10.1046/j.1523-1739.2003.02017.x

Uğurlu S, Polat N. 2007. Samsun ili tatlı su kaynaklarında yaşayan egzotik balık türleri. J Fish Sci. 1(3):139-151. doi: $10.3153 /$ jfscom. 2007017

Veenvliet P. 2007. Species identity of Gambusia (Pisces: Poeciliidae) introduced to Slovenia. Natura Sloveniae. 9(1):43-46.

Walters DM, Freeman, BJ. 2000. Distribution of Gambusia (Poeciliidae) in a Southeastern River System and the use of fin ray counts for species determination. Copeia 2000(2):555-559 doi:10.1643/0045-8511(2000)000[0555:DOGPIA]2.0.CO;2

Walton WE, Henke JA, Why AM. 2012. A Handbook of Global Freshwater Invasive Species. In: Robert A. Francis, editor. Gambusia affinis (Baird \& Girard) and Gambusia holbrooki Girard (mosquitofish). Chapter: 22. New York: Earthscan. s. 261-272.

Wooten MC, Scrbiner KT, Smith MH. 1988. Genetic variability and systematics of Gambusia in the Southeastern United States. Copeia 1988(2):283-289. doi: $10.2307 / 1445867$

Yeğen V, Balık S, Bostan H, Uysal R, Bilçen H. 2006. Göller Bölgesi'ndeki bazı göl ve baraj göllerinin balık faunlarının son durumu. 1. Ulusal Balıklandırma ve Rezervuar Yönetimi Sempozyumu. 7-9 Şubat. Antalya.

Yeğen V, Balık S, Bilçen E, Sarı HM, Uysal R, İlhan A, Bostan H. 2007. Afyon ili akarsularında yayılış gösteren balık türleri ve dağılımları. Türk Sucul Yaşam Dergisi Ulusal Su Günleri, Yıl:3-5, Sayı 58:419-428.

Zarev VY. 2012. Some life-history traits of Gambusia holbrooki (Pisces: Poeciliidae) from Bulgaria. Acta Zool Bulg. 64(3):263-272. 